\title{
SIMULAÇÃO DO TRANSPORTE DE MINÉRIO DE FERRO NA HIDROVIA DO ARAGUAIA-TOCANTINS
}

\section{IRON TRANSPORTATION SIMULATION IN ARAGUAIA- TOCANTINS WATERWAY}

\author{
Harlen dos Santos Lopes ${ }^{1}$; Breno Barros Telles do Carmo ${ }^{2}$; Nadja Glheuca da Silva Dutra ${ }^{3}$; \\ Heráclito Lopes Jaguaribe Pontes ${ }^{4}$ \\ ${ }^{1}$ Universidade Federal do Ceará - UFC - Fortaleza - Brasil \\ harlen@det.ufc.br \\ ${ }^{2}$ Universidade Federal Rural do Semi Árido - UFERSA - Mossoró - Brasil \\ brenobarros@ufersa.edu.br \\ ${ }^{3}$ Universidade Federal do Ceará - UFC - Fortaleza - Brasil \\ nadja@det.ufc.br \\ ${ }^{4}$ Universidade Federal do Ceará - UFC - Fortaleza - Brasil \\ hjaguaribe@ufc.br
}

\begin{abstract}
Resumo
No Estado do Pará, inúmeras alternativas de transporte vêm sendo desenvolvidas. Destaca-se o transporte multimodal de minério de ferro pelo rio Tocantins. A carga, transportada em larga escala através do modal hidroviário, sofre transbordo rodoviário por um trecho de apenas quatro quilometros, na cidade de Tucuruí, em função do barramento do rio, decorrente da hidrelétrica. Este trabalho propõe-se à aplicação de modelagem e simulação para o diagnóstico e análise deste sistema de transporte multimodal. Inicialmente, é construído um arcabouço teórico, referente ao contexto do sistema de transporte, à modelagem e à simulação. Em seguida, são estruturados os modelos conceitual e computacional do sistema. Com o modelo computacional estruturado, são realizadas análises de sensibilidades, através de alterações nos valores de variáveis de entrada prédeterminadas. Por fim, são apresentadas sugestões e recomendações para eventuais aprofundamentos desta pesquisa.
\end{abstract}

Palavras-chave: simulação; logística; integração.

\section{Introdução}

Atualmente, os mercados se caracterizam pela sua intensa e predatória competitividade. Inseridas neles, as empresas lutam por posições privilegiadas ou, até mesmo, por sua própria sobrevivência. Esta competição é marcada pela introdução de sistemas produtivos cada vez mais eficientes, que se caracterizam pelo aumento da produtividade, pela redução de custos, por menos desperdícios e pela manutenção e/ou acréscimo de qualidade.

Assim, as atividades produtivas não existem de forma isolada (SLACK et al. 2002) e a 
integração destes elos se dá por meio da logística. As atividades devem agregar valor ao cliente (FARINA et al. 1992), dado que a atual situação de competição não permite que empresas trabalhem com atividades que gerem custos e não agreguem valor ao cliente. Yusuf et al. (2004) entendem que os clientes e a tecnologia forçam as empresas a desenvolveram atividades logísticas mais ágeis e interligadas para serem competitivas.

Nos últimos anos, a logística vem apresentando uma evolução constante, sendo hoje um dos elementos-chave na formação da estratégia competitiva das empresas. No inicio, era confundida com o transporte e a armazenagem de produtos. Hoje, ela pode ser considerada como o ponto nevrálgico da cadeia produtiva integrada, atuando em estreita consonância com o moderno gerenciamento da cadeia de suprimentos (NOVAES, 2004).

Christopher (2009) identificou alguns fatores associados ao desenvolvimento do moderno modelo de gerenciamento da cadeia de suprimentos:

- Novas regras de competição: uma organização não pode agir de forma isolada, sendo necessário criar sistemas de fornecimento com valor agregado;

- Globalização dos setores: a empresa deve ser vista dentro de um sistema global, onde recursos materiais e componentes são terceirizados no mundo todo;

- $\quad$ Pressão descendente nos preços: entrada no mercado de concorrentes globais apoiados por base manufatura de baixo custo; e

- Clientes assumindo o controle: maior exigência do cliente em relação a qualidade do produto e serviço.

Todos estes fatores citados levaram à busca por uma maior qualidade no serviço prestado, dentre eles as atividades logísticas. Dentre estas atividades, o transporte se destaca como um centro de custos, que pode representar uma vantagem competitiva, se for delineada uma estratégia. Kaplan et al. (1997) entendem que a estratégia normalmente é definida para uma unidade organizacional. Os autores entendem que as estratégias devem ser pensadas de forma individual para cada organização. Faria e Costa (2005) definem o custo logístico como aqueles em que as empresas incorrem ao longo do fluxo de materiais e bens. Assim, os mesmos autores entendem que a logística se mostra como um recurso estratégico na obtenção e sustentação de vantagens competitivas, através da possibilidade de oferecer um melhor nível de serviço ao cliente, quanto pela redução dos custos logísticos.

Segundo Fleury et al. (2002), em nações com relativo grau de desenvolvimento, o transporte é, em geral, tão responsável pela maior parcela dos custos logísticos numa empresa, quanto na participação dos gastos logísticos em relação ao Produto Interno Bruto (PIB). Por 
essas razões, existe uma preocupação contínua com a redução de seus custos. Dentro destas iniciativas, cabe destacar a integração entre os diversos modais de transporte, e o surgimento de operadores logísticos, capazes de gerar economias de escala ao compartilhar sua capacidade e seus recursos de movimentação entre vários parceiros (LOPES, 2008). Dentro desta visão de integração de recursos de transporte, existem os conceitos de transporte multimodal, que Betaglia (2003) define como sendo o movimento de cargas que utiliza diferentes modais de maneira combinada.

No Estado do Pará, a partir de meados dos anos 80, após a conclusão da Estrada de Ferro Carajás, propriedade da Companhia Vale do Rio Doce - CVRD, o minério de ferro da jazida em Carajás passou a ser escoado para exportação, através da ferrovia, até o porto de Ponta da Madeira, no Estado do Maranhão, para então ser embarcado em navios graneleiros internacionais.

Atraídos pela oferta de minério na região e pela oportunidade de beneficiamento e exponencial agregação de valor ao minério de ferro, diversos grupos empreendedores instalaram siderúrgicas ao longo da ferrovia, utilizando-se da mesma para o abastecimento do insumo principal. O ferro gusa, produzido pelas indústrias siderúrgicas do pólo de Marabá, no Pará, tem como fundamental base de produção o minério de ferro procedente da jazida de Carajás. Sua utilização é servir como matéria-prima para a produção de aço e de peças fundidas, e, por sua alta qualidade, situa-se como o mais atrativo substituto de sucata na produção desses produtos. Exportados para diversos países, os dois produtos - minério de ferro e ferro gusa - passam por transformações e são incorporados aos costumes locais na forma de novos produtos de uso comum: de carros a aviões, de fogões a computadores, além de serem largamente empregados na produção de ferragens para a construção de estruturas e fundações.

Pela expansão da indústria do minério, foi inaugurada, em 2007, uma unidade produtiva de ferro-gusa na cidade de Barcarena, estado do Pará. Também atraída pelo avanço das atividades logísticas e pela então viabilidade de transporte fluvial, bem como pelo escoamento ainda competitivo para o mercado externo (através do porto de Vila do Conde), esta unidade de produção tem previsão de, em até cinco anos, verticalizar a cadeia do ferro, construindo em seu parque industrial um complexo integrado de siderurgia, logística e atividades correlacionadas, de caráter decisivo para o desenvolvimento do Estado do Pará e da Região Norte do Brasil. Atualmente, o porto é considerado subutilizado, se comparado aos grandes portos nacionais, como Santos, Paranaguá e Tubarão.

Este estudo fundamenta-se na substituição dos modais para o transporte dos insumos. 
Se considerado o modal rodoviário, atualmente em uso para o transporte deste minério entre Marabá e Barcarena, este volume de carga significaria algo em torno de 31.250 viagens por ano (em 2008), chegando a até 156.250 viagens por ano a partir de 2012. Isto corrobora para a avaliação do volume dos impactos sociais e ambientais, acarretados pela utilização do modal.

Alternativamente, a organização buscou a solução do transporte hidroviário, que, além de acarretar impactos menores, implica em significativa economia de recursos, à medida que uma única viagem do comboio projetado para navegar no rio Tocantins significa cerca 400 caminhões a menos nas estradas.

Assim, o presente artigo tem por objetivo diagnosticar e analisar, com base na modelagem e simulação de sistemas, um sistema multimodal de transporte de minério de ferro, com o intuito de redimensionar sua capacidade produtiva, contribuindo para o planejamento logístico e auxiliando a tomada de decisão.

Inicialmente, será apresentada uma revisão da bibliografia, no sentido de contextualizar o estudo, abordando-se o transporte hidroviário, ferroviário, rodoviário e a integração modal. Em seguida, serão feitas considerações acerca de sistemas, processo de modelagem e simulação e aplicativo de simulação empregado. Em seguida, será abordada a metodologia de desenvolvimento de um estudo de simulação. Por fim, será descrita a seqüência de métodos utilizados na construção do modelo em questão. Posteriormente, serão criados diversos cenários para a operação, a fim de diagnosticar, através de análises de sensibilidade o sistema, identificar e analisar as variáveis mais relevantes para o sistema, avaliar os prováveis gargalos do processo e dimensionar o sistema de transportes estudado. Por último, serão apresentadas as conclusões do trabalho.

\section{Modais de transporte}

O transporte contribui significativamente na composição do custo final de um produto. Isso se deve a uma série de fatores que incluem desde o modal escolhido para o transporte, passando pelas taxas cobradas pelo setor, até as condições de infra-estrutura oferecidas.

A atividade produtiva tem passado por importantes mudanças nos últimos anos. A lógica de redes globais de fornecedores exige a criação de sistemas logísticos capazes de colocar insumos e componentes diretamente nos locais de produção, observados os critérios de qualidade, fluxos e prazos determinados. Em conseqüência, percebe-se, cada vez mais, a gradual reestruturação da matriz de transporte brasileira, de forma que a produção, tanto industrial como agrícola, possa atingir, de forma eficiente, a abrangência nacional e 
integração global (CNT, 2002).

A escolha do modal para o transporte de determinado produto é fundamental para a redução de custos. Ballou (2001) compartilha do pensamento que um melhor sistema de transporte contribui para o aumento da competição no mercado, garante a economia de escala na produção e reduz preços de mercadorias. Em princípio, é necessário conhecer bem suas características, bem como o tipo de carga para a qual se destina.

Atualmente, o transporte de cargas conta com quatro principais modais: rodoviário, ferroviário, hidroviário (de interior e marítimo) e aeroviário. Existe ainda o modal dutoviário, contudo, sua participação na matriz de transportes ainda é pequena, se comparada aos demais modais. Cada um oferece vantagens e desvantagens, dependendo do tipo de operação para a qual será empregado.

Em diversos países do mundo, os modais de transporte hidroviário, ferroviário e rodoviário convivem de forma harmônica, lado a lado, cada um utilizado para transporte do tipo de carga para o qual é mais adequado. As cargas que se constituem em grandes volumes e de baixo valor agregado, a exemplo dos grãos, agregados para construção, carvão, entre outros, são transportados em geral através das hidrovias, em face de seu custo unitário menor. Quando as cargas se constituem em bens de maior valor agregado, o transporte hidroviário, por seu maior tempo de percurso, torna-se menos competitivo se comparado com os outros modais. Portanto, existem cargas específicas para cada modal de transporte, de forma que eles não se tornam concorrentes, mas sim complementares (CALABREZI, 2007).

Além de desempenharem atividades isoladas, existe também a possibilidade de combinações entre esses modais, aproveitando suas características individuais. Esse intercâmbio pode ocorrer pela troca de equipamentos ou por operações de transbordo de carga em terminais. A matriz brasileira de transporte de carga está baseada no modal rodoviário, como ilustra a Figura 1.

Figura 1: Divisão participativa dos modais de transporte no Brasil.

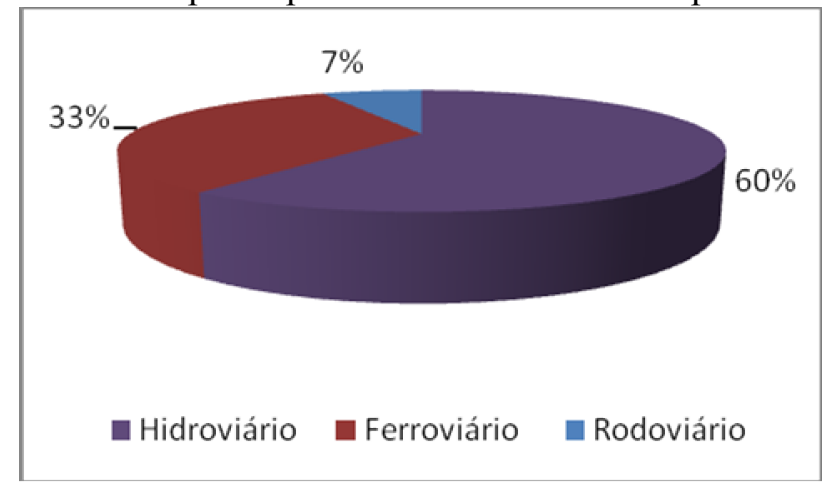

Fonte: ANTT, 2004 
A infra-estrutura ferroviária e hidroviária do País é insuficiente para realizar o transporte de granéis. Isso infelizmente faz com que seja necessária a utilização do modal rodoviário para o transporte de grande parte da produção de soja brasileira, mesmo quando se trata de longas distâncias. O problema dessa predominância também se dá pelo baixo aproveitamento do transporte, pois um caminhão carrega cerca de 150 vezes menos soja do que uma composição ferroviária e cerca de 600 vezes menos do que um comboio de barcaças numa hidrovia como a do Rio Madeira (OJIMA, 2004).

No modal ferroviário, o uso de vagões inadequados, a pequena oferta de material rodante e a baixa qualidade do existente podem ser consideradas as principais deficiências na infra-estrutura. Já para o modal hidroviário, o problema reside na baixa capacidade de intermodalidade e comboio, além de oferecer pouca atratividade de investimentos devido às barreiras ambientais.

Conforme Caixeta Filho (1996), “essa predominância do modo rodoviário pode ser explicada pelas dificuldades que outras categorias de transporte enfrentam para atender eficientemente aos aumentos de demanda em áreas mais afastadas do País, as quais não são servidas por ferrovias ou hidrovias".

Mas, a tocante infra-estrutura não é o único problema. No setor ferroviário, por exemplo, há a questão da interação entre as concessionárias ferroviárias. Muitas delas detêm trechos que interligam os portos de exportação e que precisam ser partilhados; porém, muitas vezes, os altos fretes cobrados nesses trechos podem inviabilizar o transporte.

A decisão de um usuário para a movimentação de sua carga depende, basicamente, de dois fatores: os custos e as características operacionais do serviço de transporte.

Fleury (2002) explana que são cinco as dimensões mais importantes, no que diz respeito às características dos serviços oferecidos: velocidade, consistência, capacitação, disponibilidade e freqüência. Estas características são fundamentais, de acordo com as proporções de necessidades de transporte, para a escolha adequada do modal a transportar. Nesta análise, o autor insere os modais dutoviário e aeroviário.

A velocidade refere-se ao tempo do percurso entre a origem e o destino de um transporte, também conhecido como transit time, sendo o modal aéreo o mais rápido de todos. E, ainda, considera-se o tempo gasto no embarque e desembarque da carga (NAZÁRIO et al., 2000; FLEURY, 2002).

"A consistência, que representa a capacidade de cumprir os tempos previstos, tem o duto como a melhor opção. Por não ser afetado pelas condições climáticas ou de congestionamentos, o duto apresenta uma alta consistência. Já o baixo desempenho do aéreo é 
resultante de sua grande sensibilidade a questões climáticas e sua elevada preocupação com questões de segurança" (FLEURY, 2002).

A capacitação representa a habilidade do modal em movimentar diferentes volumes e variedades de produtos. Assim, o destaque fica para o modal aquaviário, que praticamente não possui limitações para o tipo de produto e volume a ser transportado (FLEURY, 2002).

“A dimensão disponibilidade se refere ao número de localidades onde o modal se encontra presente. Aqui, aparece a grande vantagem do rodoviário, que quase não tem limites de onde pode chegar (porta a porta). Teoricamente, o segundo em disponibilidade é o ferroviário, mas isto depende da extensão da malha ferroviária em um determinado país" (FLEURY, 2002).

Com relação à dimensão freqüência, ou seja, o número de viagens em um período de tempo, o duto é o que apresenta o melhor desempenho, pode operar durante 24 horas por dia e ser solicitado a qualquer momento, desde que esteja disponível no local desejado (FLEURY, 2002).

Assim, é importante conhecer as características descritas acima no momento da escolha do modal viário para o transporte de determinada carga, identificando as vantagens e desvantagens de cada modal e as características da carga a ser transportada, na tentativa de estabelecer uma rota ótima para um determinado fluxo de transporte.

\subsection{Modal hidroviário}

O transporte hidroviário é um dos mais econômicos meios de movimentação de bens e pessoas. É o que exige menor consumo de combustíveis, em relação à capacidade de carga e deslocamento (permite maior ganho em escala). Oliva (2008) corrobora com o pensamento quando afirma que o transporte hidroviário é o modal mais economicamente viável e eficiente, que exige menos investimentos nas fases de implantação e manutenção e acarreta baixo impacto ambiental relativamente aos demais modais. Estes fatos são ilustrados na Figura 1. 
Figura 1: Consumo e potência dos modais de transporte

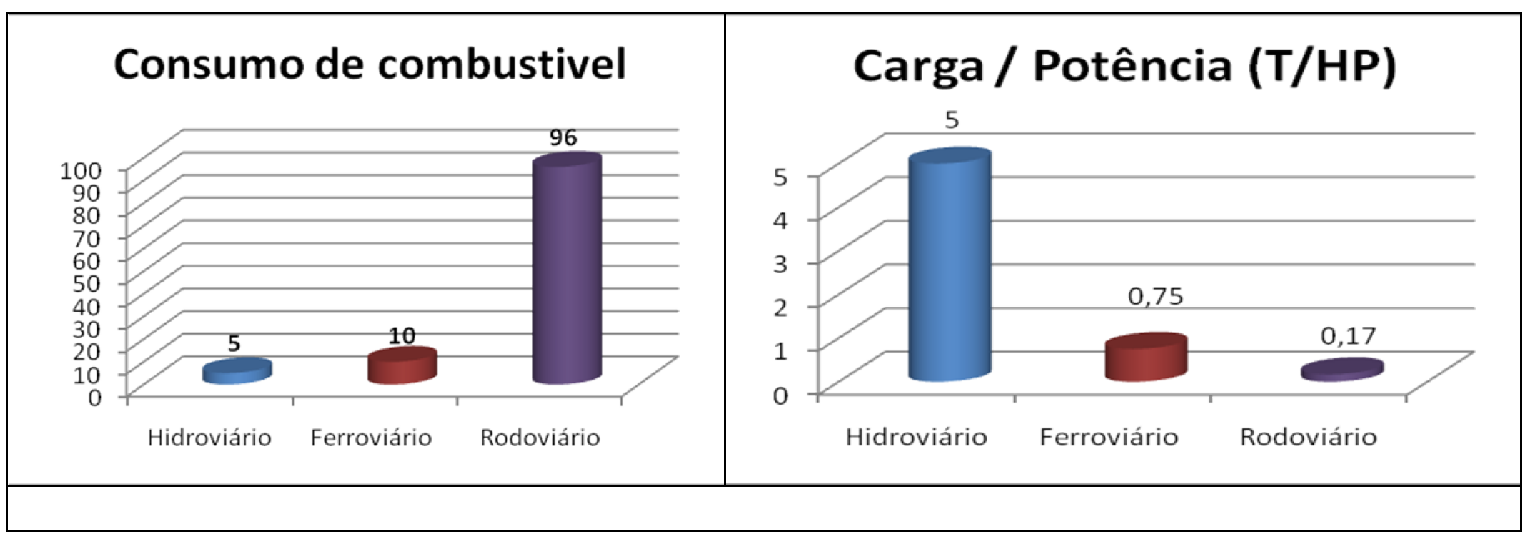

Fonte: Ministério dos Transportes (2007)

A navegação, em especial a navegação fluvial, é amplamente utilizada desde os primórdios de nossa civilização. Países como a China, toda a Europa, os Estados Unidos e o Canadá fizeram de suas redes hidroviárias meios eficientes e econômicos de transporte, em contínua modernização e atualização tecnológica, inclusive quanto à compatibilidade com o meio ambiente natural (RESENDE, 2007).

Caixeta Filho (1996) argumenta que a não existência de rios navegáveis que desemboquem no oceano é a principal razão de o Brasil não ter um sistema aquaviário que venha solucionar o problema de transporte, a exemplo do que acontece nos EUA. Os rios brasileiros, com exceção do sistema Tietê-Paraná, não estabeleceram ligações entre centros econômicos importantes. Isso torna necessário várias operações de transbordo para que o produto chegue ao destino final. A trafegabilidade, em termos dos regimes observados (intermitentes e perenizados), também deve ser considerada.

Considerado um dos maiores sistemas aquaviários do mundo, o sistema hidroviário brasileiro contém 8 bacias hidrográficas, onde são movimentadas mais de meio milhão de toneladas de cargas por ano. Não obstante, possui cerca de 13 mil km de vias navegáveis utilizadas economicamente para o transporte de cargas e passageiros, podendo atingir cerca de 44 mil km navegáveis, caso sejam realizadas obras de infra-estrutura em outros 29 mil km de vias naturalmente disponíveis, sem contar que o país possui potencial de navegabilidade em águas superficiais fluviolacustres em cerca de 63.000km (ANTT, 2004).

Apesar do grande potencial da malha hidroviária brasileira, a ausência de um nível adequado de investimentos no setor tem resultado em prejuízos para a viabilidade econômica das vias navegáveis, concorrendo para o desbalanceamento da matriz de transportes e para o agravamento das deficiências na intermodalidade com os demais modais. $\mathrm{O}$ aproveitamento 
adequado das vias navegáveis depende da realização de obras de infra-estrutura, tais como dragagem; transposição de trechos não navegáveis, por meio de eclusas e canais artificiais de transposição; derrocamentos de obstáculos naturais; e balizamento e sinalização (CNT, 2002).

\subsection{Modal ferroviário}

A infra-estrutura ferroviária e hidroviária do País é insuficiente para realizar o transporte de granéis. Isso faz com que seja necessária a utilização do modal rodoviário para o transporte de grande parte da produção de soja brasileira, mesmo quando se trata de longas distâncias. O problema dessa predominância também se dá pelo baixo aproveitamento do transporte, pois um caminhão carrega cerca de 150 vezes menos soja do que uma composição ferroviária e cerca de 600 vezes menos do que um comboio de barcaças numa hidrovia como a do Rio Madeira (OJIMA, 2004).

Conforme Caixeta Filho (1996), “essa predominância do modo rodoviário pode ser explicada pelas dificuldades que outras categorias de transporte enfrentam para atender eficientemente aos aumentos de demanda em áreas mais afastadas do país, as quais não são servidas por ferrovias ou hidrovias".

Mas, a infra-estrutura não é o único problema. No setor ferroviário, por exemplo, há a questão da interação entre as concessionárias ferroviárias. Muitas delas detêm trechos que interligam os portos de exportação e que precisam ser partilhados; porém, muitas vezes, os altos fretes cobrados nesses trechos podem inviabilizar o transporte.

A decisão de um usuário para a movimentação de sua carga depende, basicamente, de dois fatores: os custos e as características operacionais do serviço de transporte (FARIA; COSTA, 2005).

Fleury (2002) explana que são cinco as dimensões mais importantes, no que diz respeito às características dos serviços oferecidos: velocidade, consistência, capacitação, disponibilidade e freqüência. Estas características são fundamentais, de acordo com as proporções de necessidades de transporte, para a escolha adequada do modal.

\subsection{Modal rodoviário}

Faria e Costa (2005) ratificam que o modal rodoviário é o mais utilizado no contexto brasileiro. Em tese, os mesmos autores definem que este tipo de transporte deveria ser utilizado para cargas pequenas e médias, para curtas e médias distâncias, com coleta e entrega ponto a ponto. Porém, o que se observa no Brasil é que este modal é largamente utilizado, 
independentemente das características da mercadoria e da distância. Isso se dá pela infraestrutura disponível, que favorece este modal.

Bertáglia (2003) advoga que o este tipo de modal é mais independente dentre os existentes dada a disponibilidade de entrega ponto a ponto. A grande questão levantada por este autor é a situação da malha viária brasileira, que encarece o custo deste modal, apesar dele se apresentar como sendo o mais viável dentre as possibilidades brasileiras.

A grande vantagem deste modal, identificada por Bertáglia (2003) é a capacidade de fazer a conexão entre os diferentes modos de transporte e seus respectivos pontos de embarque e desembarque. A idéia do presente artigo se baseia neste conceito, onde para realizar o transporte no caso analisado, faz-se necessário a integração dos modais via modal rodoviário. Este tipo de característica garante um maior ganho de eficiência e redução de custos, pela adoção, em grande parte da viagem, de modais com menor custo, com a capacidade de entrega porta a porta.

\section{Sistemas, modelagem e simulação}

De acordo com Silva (2002), um sistema pode ser definido como um grupo de objetos, como pessoas ou máquinas, reunidos em alguma interação ou interdependência regular, a fim de se alcançar algum objetivo ou propósito lógico.

Através dessa definição, nota-se que um sistema é algo bastante relativo. Em determinado momento, uma coleção de objetos pode ser uma pequena parte de um sistema maior (subsistema), e em outro é considerada um sistema completo. Os limites do sistema são estabelecidos a fim de se definir o que será estudado e incluir neles apenas aqueles itens que são considerados mais importantes para os objetivos. A determinação desses limites depende do estudo realizado e dos objetivos a serem alcançados. Deste modo, o termo endógeno é usado para descrever atividades e eventos do ambiente que afetam o sistema (BANKS et al., 2003).

Ainda de acordo com Banks et al. (2003), para se compreender e analisar um sistema, alguns termos precisam ser definidos. Uma entidade é um objeto de interesse no sistema e um atributo é uma propriedade de uma entidade. Uma atividade representa um período de tempo de duração especificada; já um evento pode ser definido como uma ocorrência instantânea, que pode mudar o estado do sistema. Se uma linha de produção está sendo estudada, os produtos poderão ser entidades, seus tempos de processamento poderiam ser um atributo, e a transformação dos produtos poderia ser uma atividade. 
O estado de um sistema é outro componente que pode ser definido, segundo Law \& Kelton (2000), como uma coleção de variáveis necessárias para descrever um sistema em determinado momento. No estudo de um banco, são possíveis variáveis de estado: o número de atendentes ocupados, o número de clientes esperando na fila ou sendo servidos e o tempo de chegada do próximo cliente.

Um sistema pode ser estudado em forma de um modelo. Forrester (1991) diz que os modelos têm se tornado largamente aceitos como um meio de estudar fenômenos complexos, e que seu valor provém da melhoria da compreensão das características de comportamento do sistema real, compreensão essa mais efetiva do que aquela realizada pela observação do sistema em si. Um modelo, comparado ao sistema real que ele representa, pode lidar com informação a um baixo custo, além de o conhecimento ser obtido mais rapidamente e em condições não observáveis na vida real.

A partir de uma abstração do problema, é gerado o modelo, onde são envolvidas as variáveis consideradas. O nível de complexidade do modelo é diretamente proporcional à abstração efetuada, ou seja, ao número e a quais características serão utilizadas para a abstração (LOBATO, 2000).

$\mathrm{Na}$ modelagem de sistemas, essas características são chamadas de variáveis do problema, uma vez que assumem diversos valores durante o desenvolvimento da solução e influenciam diretamente o sistema. Andrade (2004) classifica as variáveis em três categorias: a) variáveis de decisão; b) variáveis controláveis ou endógenas e c) variáveis não controláveis ou exógenas.

O modelo mais apropriado para um dado contexto depende de fatores como, natureza matemática das relações entre variáveis, objetivos, nível de controle sobre as variáveis e de incertezas associadas ao ambiente. Partindo dessas considerações podemos dividir os modelos matemáticos em dois grandes grupos: de otimização e de simulação.

Os modelos de otimização são estruturados para obtenção, segundo alguns critérios estabelecidos pelo analista, de uma solução ótima, que servirá como referência para a decisão real. Essa alternativa é resultado de uma análise matemática, processada por métodos sistemáticos de solução, chamados de algoritmos (SALIBY et al., 2001)

Já os modelos de simulação oferecem uma maior flexibilidade ao analista. Esses modelos propõem uma representação da realidade com o objetivo de analisar diversas alternativas antes da implementação de qualquer uma delas. Essa flexibilidade permite ao analista criar possíveis ambientes futuros e testar alternativas, ou seja, o critério de escolha da melhor alternativa não está fixado na estrutura do modelo (SILVA, 2002) 
Segundo Soares (1992), os modelos são uma descrição dos sistemas e, apesar de serem construídos dependentes do problema a resolver, requerem uma estrutura organizada qualquer. Uma linguagem (ou pacote) para simulação fornece uma destas estruturas, e é sua compilação que vai traduzir a descrição do sistema em uma forma aceitável por um sistema de computação.

Dessa maneira, a simulação pode ser encarada como uma metodologia experimental e aplicada, em que é necessário o uso de uma abordagem sistêmica, pois se busca analisar o desempenho total do sistema, e não apenas de suas partes. Isso significa que, quando se tem uma parte do sistema otimizado, não necessariamente o desempenho global também estará funcionando da mesma forma; é preciso observar a interação das partes (HARREL et al., 2002)

Pedgen et al. (1995), definem que simulação "é o processo de elaborar um modelo de um sistema real e conduzir experimentos, com o propósito de compreender o comportamento do sistema e/ou avaliar várias estratégias para a operação do mesmo". Prado (1999) entende simulação como a técnica de solução de um problema pela análise de um modelo que descreve o comportamento do sistema usando um computador digital. Assim, Botter (2001), entende que a simulação tem de ter por objetivo a descrição do comportamento de sistemas; a construção de teorias ou hipóteses que explicam o comportamento observado; o uso do modelo para prever um comportamento futuro.

Logo, a simulação é uma abordagem geral para o estudo de problemas complexos, para os quais a solução analítica é excessivamente complexa ou restritiva em relação às características do problema real. Num contexto mais amplo, a simulação refere-se à construção de modelos de qualquer natureza (físicos, matemáticos, lógicos, idealizados) e na condução de experimentos com estes modelos para o estudo de uma ou mais variáveis de interesse. Com as facilidades computacionais atuais, a simulação vem se mostrado uma ferramenta cada vez mais potente para o auxílio de tomadas de decisão em sistemas de transportes, permitindo uma rapidez maior na escolha de alternativas operacionais.

A simulação, por ser uma técnica de Pesquisa Operacional, utiliza-se do método científico para desempenhar seu papel. Um processo de simulação se baseia numa série de etapas, que pode ser chamada de metodologia de simulação. As bibliografias a respeito da metodologia de um estudo de simulação, em geral, são semelhantes, diferindo em detalhes com relação a etapas a serem seguidas. 


\section{Metodologia}

A simulação, por ser uma técnica de Pesquisa Operacional, utiliza-se do método científico para desempenhar seu papel. Um processo de simulação se baseia numa série de etapas, que pode ser chamada de metodologia de simulação. Andrade (2004), conforme mostrado na Figura 3, esboça o fluxo da metodologia de simulação, utilizada também no presente trabalho.

É importante que alguns critérios sejam seguidos para um estudo de simulação:

- $\quad$ Levantamento de todas as variáveis que possam interferir no sistema;

- $\quad$ Conhecimento da área a ser analisada;

- $\quad$ Entrosamento entre as pessoas envolvidas no trabalho e a empresa na qual será realizado o estudo;

- $\quad$ Disponibilidade de recursos (pessoal, tempo, informações, tecnologia).

Figura 3: Diagrama das etapas de um estudo de simulação

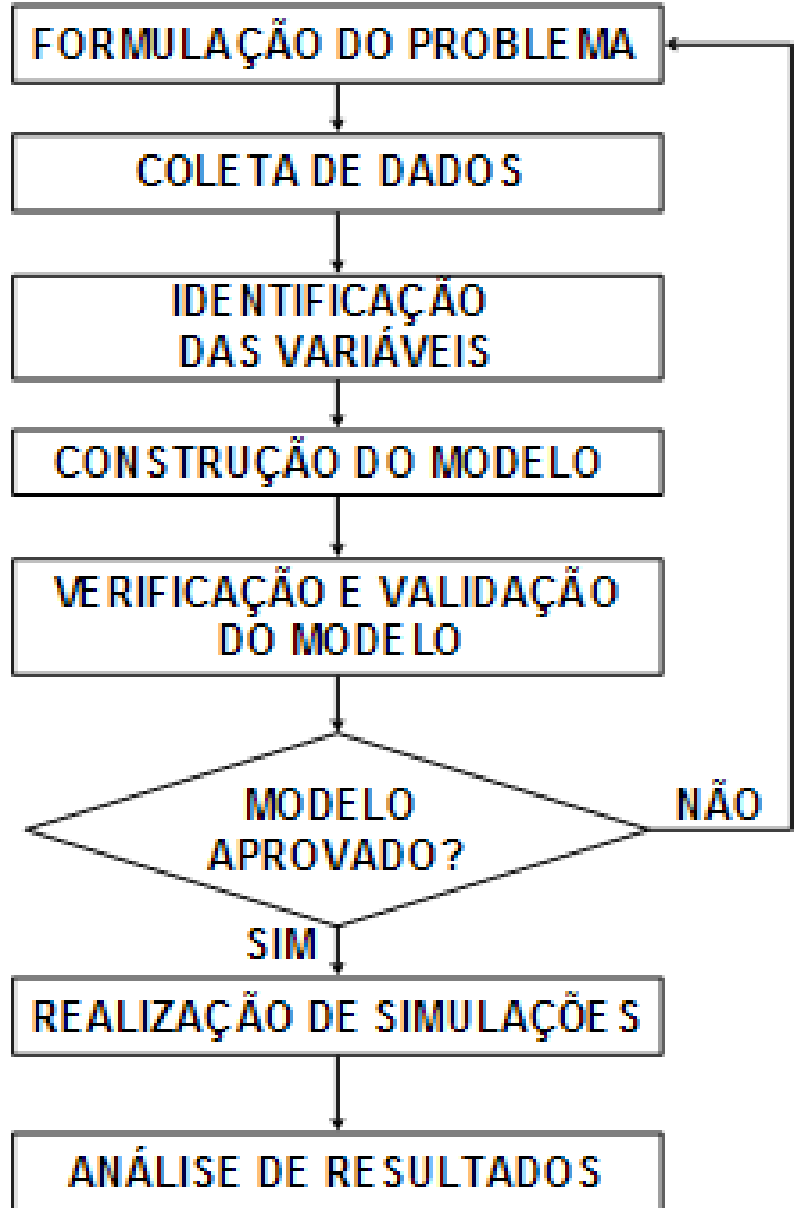

Fonte: Andrade (2004)

Um experimento de simulação computacional deve iniciar-se com a formulação do problema e com o planejamento do estudo. Isto porque a obtenção de uma solução aceitável 
depende de um bom conhecimento do problema e da criação de um plano para sua avaliação. Primeiramente, deve-se possuir um pleno conhecimento das partes que compõem um sistema, e deste como um todo. Devem ser definidas claramente as metas do estudo, o porquê se estar estudando este problema, quais respostas pretendem-se encontrar e a amplitude e profundidade que se quer ter da análise do sistema. A definição do problema pode estar sujeita a alterações durante a realização do problema, já que o modelo passará por teste e modificações.

Na etapa de identificação das variáveis, verifica-se a existência de recursos físicos, humanos e técnicos para a execução o projeto. Ainda nesta etapa, selecionam-se as medidas de eficiência empregadas e os fatores a serem variados. Após ter detalhado o sistema, ainda sem os termos de um software de simulação ou linguagem de programação, pode-se definir estações, recursos, transportadores, velocidades, filas e espaços disponíveis. É importante definir também as relações entre as variáveis, as condições e restrições do sistema, de modo a possibilitar a construção do modelo que represente, o mais fielmente possível, sua operação no mundo real.

A coleta de dados se refere a dados quantitativos e qualitativos sobre as entradas e saídas do sistema, bem como informações sobre os componentes do sistema e suas interconexões ou relações. O modelador deve decidir que dados são necessários, se são pertinentes, se são válidos e como foram obtidos e validados.

Para a coleta de dados, o grupo ou a pessoa que irá trabalhar deve ter conhecimento sobre as etapas anteriores; do contrário, os resultados podem sofrer variações inesperadas, normalmente causadas por diferenças entre percepções de cada pessoa sobre o sistema.

A coleta de dados é uma atividade que influi diretamente na formulação do problema, uma vez que possibilita definir o escopo do modelo, sua validade e, até mesmo, o grau de confiabilidade dos resultados obtidos ao final da simulação.

Para a criação de um modelo matemático, deve ser construído, após o levantamento de dados e coleta de informações referentes ao processo estudado, um modelo conceitual da operação, o qual conterá informações e explicações teóricas empregadas para auxiliar o entendimento do determinado sistema, visando permitir o desenvolvimento controlado e consistente do modelo computacional com os objetivos do projeto.

Uma vez construído o modelo, é necessário saber se ele atende aos objetivos da simulação, representando corretamente o sistema em estudo. Os testes com o modelo devem abranger também os dados, de modo a se poder verificar sua consistência. A realização das simulações consiste em executar os experimentos de simulação, reproduzindo a situação 
atual, realizando cenários com configurações ou alterações futuras que se deseja estudar.

Por último, são analisados os dados de saída do modelo, a partir das configurações definidas no início da replicação. Podem ser feitas diversas modificações e simulações de tempos futuros, com o intuito de comparar os resultados.

\section{Estudo de caso}

\subsection{Caracterização do sistema em estudo}

O sistema estudado trata de uma operação logística de granéis sólidos - mais precisamente, minério de ferro granulado - com origem na cidade de Marabá, no Pará, e destino à cidade de Barcarena, no distrito industrial de Vila do Conde, também no estado do Pará.

O transporte utilizará, quase em sua totalidade, o modal hidroviário. Entretanto, em função do barramento do Rio Tocantins, ocasionado pela construção da Usina Hidrelétrica de Tucuruí, faz-se necessário o transbordo rodoviário de toda a carga que se pretenda transportar (no trecho da barragem), conforme a Figura 4.

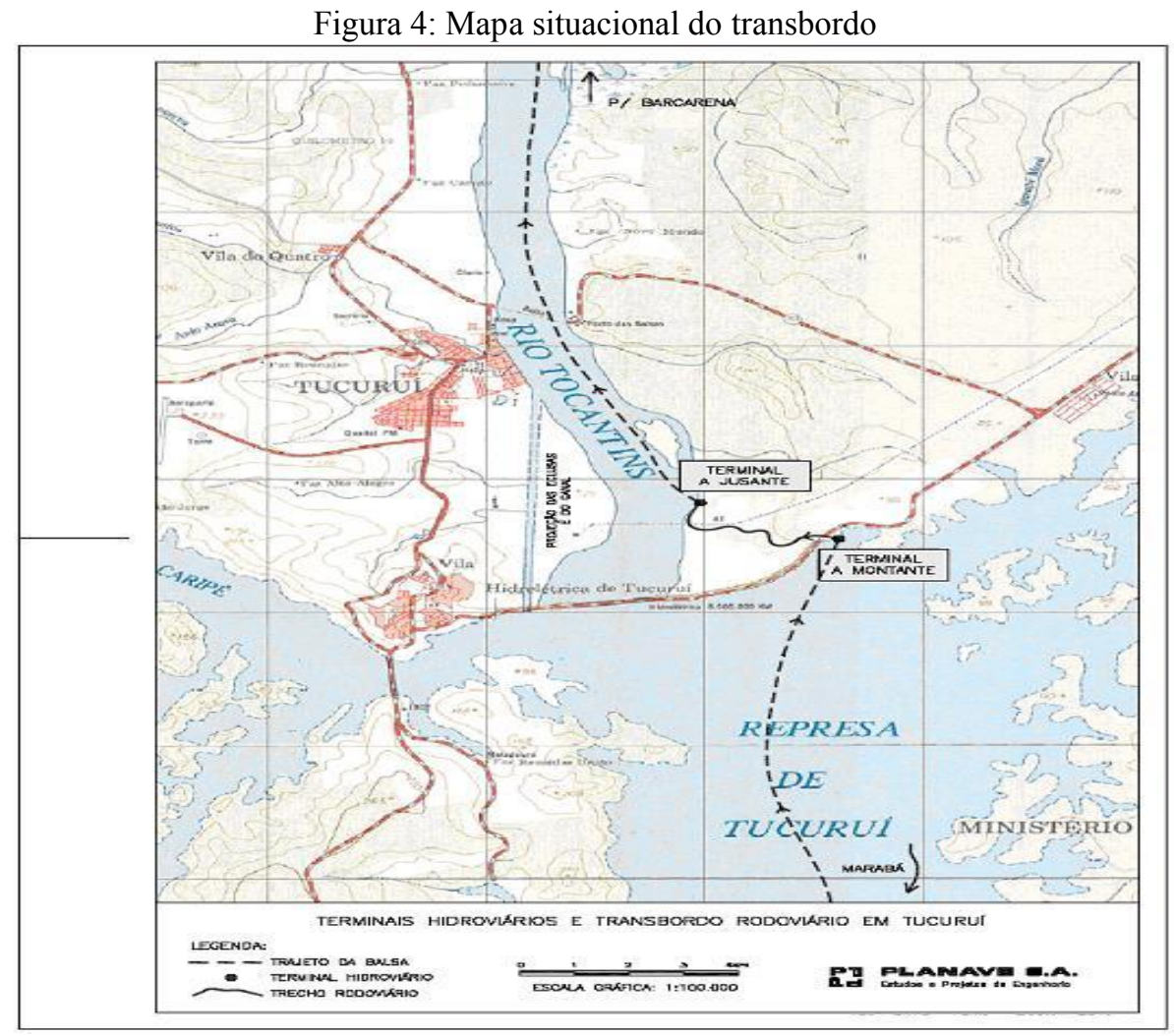

Fonte: Planave (2004)

No sistema estudado, o produto é carregado em barcaças, em um terminal hidroviário, na cidade de Marabá que, por sua vez, depois de carregadas, descem o rio Tocantins, tendo 
como destino o final do lago da represa de Tucuruí, à montante da barragem da hidrelétrica. Neste ponto, através de outro terminal hidroviário, os produtos são desembarcados e transportados via rodoviária até outro terminal, à jusante da barragem, em caminhões basculantes, por um percurso de $4 \mathrm{~km}$, para um pátio de estoque intermediário ao sistema, às margens do segundo trecho do Rio Tocantins. Neste pátio, o produto transportado é provisoriamente armazenado até a chegada de outro comboio de barcaças. Quando da chegada deste comboio, o produto embarca novamente em mais um terminal hidroviário, carregando as barcaças do trecho abaixo da hidrelétrica, descendo, ainda através da Hidrovia do Tocantins, até um terminal hidroviário, situado dentro de uma usina siderúrgica, em Barcarena.

Os recursos usados pelo sistema foram definidos como as barcaças, que transportam a carga no modal hidroviário, e os caminhões, que transportam a carga no modal rodoviário. Para modelar o sistema, considerou-se 1 (uma) tonelada de minério de ferro como a entidade temporária do sistema. Esta entidade provém de uma fonte e, depois de transportado, deixa o sistema.

\subsection{Caracterização do modelo}

Com a caracterização do sistema em estudo, foram identificadas todas as variáveis componentes do sistema, divididas em "variáveis de entrada" e "variáveis de saída". As variáveis de entrada são que deram base à coleta de dados. Através da inserção dos parâmetros no modelo computacional, encontram-se as variáveis de saída, fundamentais para a comparação entre cenários. No estudo deste sistema, as variáveis consideradas são os dados de entrada para o modelo e os dados de saída gerados pelo software EXTENDTM, conforme mostra a Tabela 1.

Tabela 1: Variáveis de entrada e saída do modelo

\begin{tabular}{ll}
\hline & Carga expedida por semana \\
& Quantidade carregada por comboio - Montante e Jusante \\
& Tempo de carregamento - Comboios de Montante e de Jusante e Caminhões \\
& Barcaças por Comboio \\
& Tempo de viagem ida - Comboios de Montante e de Jusante e Caminhões \\
& Tempo de viagem volta - Comboios de Montante e de Jusante e Caminhões \\
VARIÁVEIS DE & Caminhões disponíveis \\
ENTRADA & Carga por caminhão \\
& Quantidade de produto no pátio de estoque \\
& Tempo de descarregamento do comboio \\
& Quantidade de Produto Embarcado - Porto Marabá e Porto Tucuruí
\end{tabular}


Total de Barcaças Carregadas - Porto Marabá e Porto Tucuruí

Número de Partidas de Comboio - Montante e Jusante

Número de Retornos de Comboio - Montante e Jusante

VARIÁVEIS DE

SAÍDA
Índice de Utilização - Comboios de Montante e de Jusante e Caminhões

Número de Viagens de Ida - Comboios de Montante e de Jusante e Caminhões

Número de Viagens de Volta - Comboios de Montante e de Jusante e Caminhões

Quantidade de Produto Recebida - Porto Tucuruí e Porto Barcarena

Quantidade de Produto Transportado em Caminhões

Total de Caminhões Carregados

Tempo de Descarga dos Comboios

Tempo Total da Operação

A coleta de dados foi realizada in locu, através do preenchimento de planilhas, com o envolvimento do setor operacional da companhia envolvida. Foram coletadas também informações em relatórios, projetos e levantamentos feitos por empresas envolvidas com o sistema. Foram consultados relatórios e projetos conceituais de empresas de consultoria, empresas transportadoras, fornecedores e clientes da futura operação.

Com os dados levantados, foi construído o modelo conceitual, visando posterior realização de uma simulação em linguagem EXTENDTM, refere-se a um período de operação de transporte de minério de ferro granulado, através da Hidrovia Araguaia-Tocantins.

Silva (2002) entende que o EXTENDTM é uma linguagem de simulação do tipo orientada a objeto. Esta classificação significa um grande apelo visual para o entendimento do funcionamento de sistemas. O software pode ser utilizado tanto para implementar modelos discretos, quanto para modelos contínuos.

O usuário pode empregar o EXTENDTM em três diferentes formas: (i) utilizando modelos implementados, (ii) criando seus próprios modelos a partir de blocos padrões disponibilizados pelo EXTENDTM e (iii) programando novos blocos ou modificando os códigos dos blocos existentes na implementação de seus modelos (RIVERA, 1997; KRAHL, 2000).

Para a construção do modelo conceitual, assim como do modelo de simulação, utilizou-se o método de se iniciar com um modelo simples e depois aumentar sua complexidade progressivamente. Neste item, houve o cuidado de se garantir um nível apropriado de complexidade do modelo, pois modelos muito complicados apenas acrescentam esforço computacional, enquanto que modelos muito simples não representam adequadamente o sistema. A Figura 5 descreve, através da cadeia logística do minério de ferro, a operação estudada. 


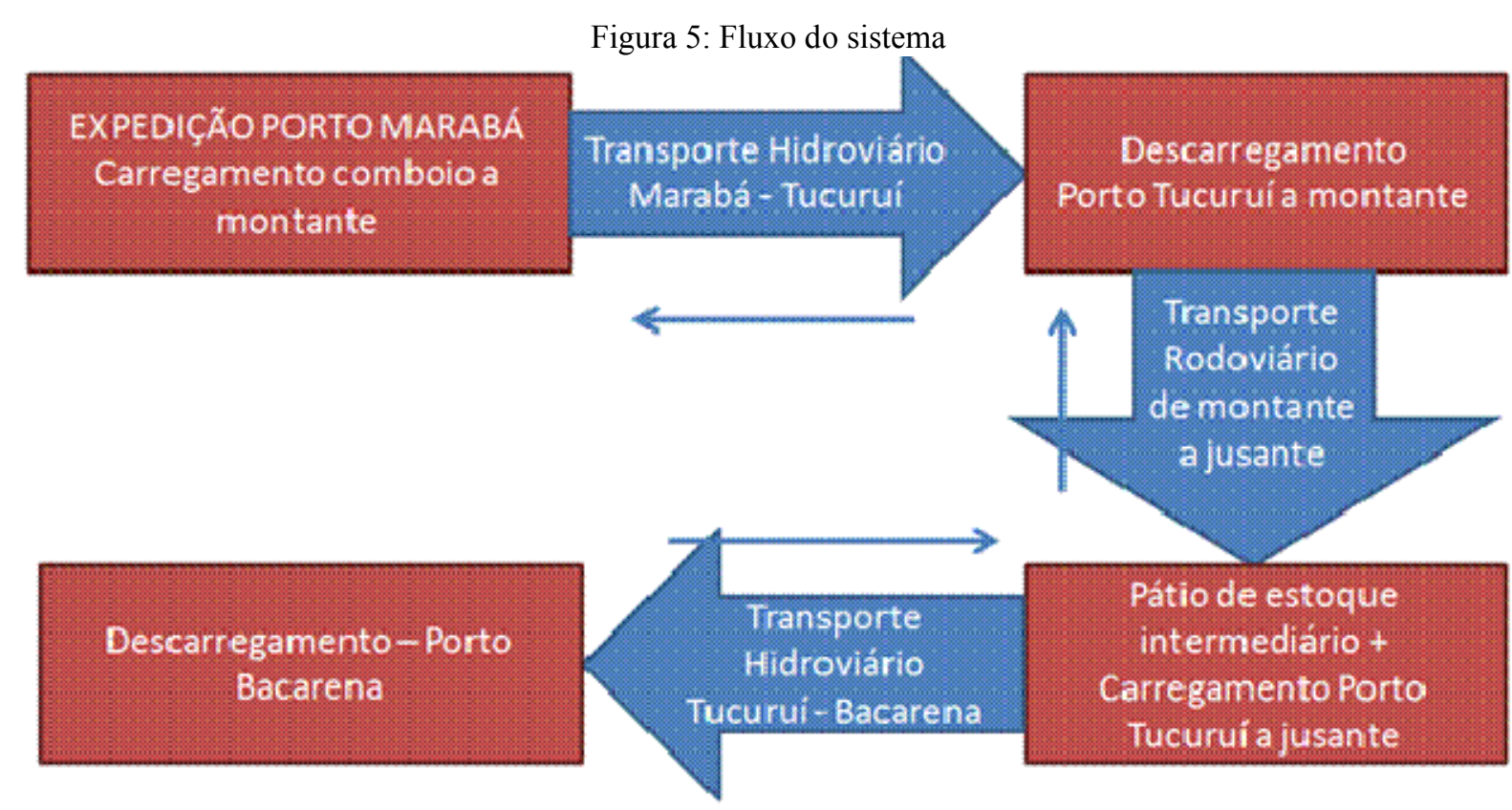

O sistema estudado tem início na cidade de Marabá, pólo siderúrgico da região dos Carajás, no estado do Pará. Neste ponto, durante o período de atracação das barcaças, os produtos serão carregados em ritmo intenso de um pátio de estoque situado no terminal fluvial à margem esquerda do Rio Tocantins através de carregadores específicos para navios e barcaças, os ship loaders. As barcaças, então, sairão totalmente carregadas em comboios de 8 unidades para cada empurrador marítimo, e descerão o rio Tocantins até o Lago de Tucuruí, acima da barragem da hidrelétrica. As barcaças projetadas e adquiridas para a operação são do tipo Araguaia - projetadas de acordo com as restrições de navegação no rio Araguaia, componente limitante da hidrovia Araguaia-Tocantins -, possuem em torno de 625ton de capacidade, $45 \mathrm{~m}$ de comprimento (pontal), $11 \mathrm{~m}$ de largura (boca) e $1,5 \mathrm{~m}$ de altura (calado). $\mathrm{O}$ trecho entre as duas cidades possui $215 \mathrm{~km}$.

Na chegada à cidade de Tucuruí, os produtos serão desembarcados em um terminal hidroviário e transportados via rodoviária, por um percurso de $4 \mathrm{~km}$, até um outro terminal hidroviário abaixo da barragem da hidrelétrica. O descarregamento das barcaças será feito através de caminhões, que entrarão nas barcaças e serão totalmente carregados por pás carregadeiras e retroescavadeiras. Os caminhões, após totalmente carregados, dirigir-se-ão até um pátio de estoque intermediário situado no outro terminal, também à jusante.

Um dos pontos cruciais do sistema estudado é a quantidade ideal de caminhões necessária para a operação, uma vez que os comboios hidroviários, devido a seus altos valores agregados (de acordo com as empresas consultadas), nos dois trechos, não podem ficar ociosos, à espera de caminhões. Por este motivo, este trabalho objetiva também estimar a 
frota ideal de caminhões para a operação.

O pátio de estoque intermediário, também em função da não ociosidade dos comboios, será um dos focos deste trabalho e será dimensionado de forma que não falte e nem sobre (em demasia) estoque de produtos.

Para o carregamento do comboio em Tucuruí, os produtos serão carregados em ritmo intenso do pátio de estoque para as barcaças, também através de ship loaders. No trecho que vai da cidade de Tucuruí até a cidade de Barcarena, as barcaças sairão totalmente carregadas em comboios de 4 unidades para um empurrador e descerão novamente o rio Tocantins por, aproximadamente, $280 \mathrm{~km}$ até um terminal hidroviário, situado nas instalações de uma usina siderúrgica. As barcaças projetadas e adquiridas para a operação são do tipo Mississipi, possuem em torno de 1750 ton. de capacidade, 60m de comprimento (pontal), 10,67m de largura (boca) e $3,5 \mathrm{~m}$ de altura (calado).

Para o descarregamento, na cidade de Barcarena, nas instalações da companhia, adotar-se-á um sistema de moegas que descarregarão o minério de ferro para correias transportadoras.

De posse do modelo conceitual, do fluxograma do sistema, das variáveis pré-definidas, dos dados coletados e suas análises, foi então implementado um modelo de simulação computacional. Este modelo pode ser considerado da seguinte maneira:

- dinâmico, tendo em vista ser possível retratar a situação do sistema ao longo do tempo;

- $\quad$ estocástico (suas variáveis são do tipo aleatório)

- $\quad$ discreto, porque o fluxo de material foi dividido em incrementos (entidades) correspondentes a uma tonelada - para simular o transporte de granéis entre as cidades de Marabá e Barcarena, envolvendo os modais hidroviário e rodoviário.

Na implementação do modelo, foi utilizada a linguagem de simulação EXTENDTM, sendo construídos sete blocos do tipo hierárquicos, os quais podem ser visualizados na Figura 3. Estes foram denominados: Porto de Marabá; Comboio M; Atracadouro Montante; Caminhões; Porto Jusante; Comboio J e Porto de Barcarena. Estes blocos relacionam-se às etapas consideradas na Figura 5, subdivisões do sistema estudado. A relação entre os blocos do modelo computacional e as etapas do sistema pode ser visualizada na Tabela 2.

Tabela 2: Relação entre blocos hierárquicos e etapas do sistema.

BLOCO

HIERÁRQUICO

ETAPA

Porto de Marabá

Porto Marabá 


\begin{tabular}{ll} 
Comboio M & Transporte Marabá-Tucuruí \\
Atracadouro Montante & Porto Tucuruí Montante \\
Caminhões & Transporte Caminhões \\
Porto Jusante & Porto Tucuruí Jusante \\
Comboio J & Transporte Tucuruí-Barcarena \\
Porto de Barcarena & Porto Barcarena \\
\hline
\end{tabular}

Internamente, cada um destes blocos é constituído por blocos menores, disponibilizados em bibliotecas do software EXTENDTM. Estes blocos, chamados de "blocos código" foram selecionados das bibliotecas Discrete Event, Generic e Manufacturing, com base em suas características em relação à linguagem de simulação e arranjados na tela de acordo com o leiaute proposto para o sistema. Em seguida, os blocos foram ligados através de conectores conforme a lógica do sistema estudado. Os dados de entrada são inseridos no modelo de acordo com as distribuições de probabilidade previamente obtidas.

O software EXTENDTM permite que possa ser observada, já durante a simulação do modelo, a movimentação dos produtos ou entidades, a passagem de itens, a quantidade de itens, a variação do nível de estoque e a possível formação de filas de recursos (caminhões e barcaças) no carregamento ou descarregamento de materiais. O software oferece também, além de outros recursos, a possibilidade de acompanhar o momento em que ocorre cada evento, através de um relógio e de um calendário.

A Figura 6 representa as informações referentes ao bloco hierárquico "Atracadouro à Montante", que representa o terminal de descarga à montante da barragem da usina. No lado esquerdo da tela, pode-se observar uma das grandes funções do EXTENDTM para o suporte à tomada de decisões: a partir de um cursor específico para a "clonagem" de janelas de resultados, é possível o agrupamento de dados que se pretenda analisar em uma nova janela, e, acompanhar suas variações durante o período de simulação. Pode-se observar, conforme a amostra do sistema, que, às 35,7 horas de tempo real, chegaram a este terminal 5.120 toneladas, das quais 2.838 foram descarregadas por caminhões em 105 viagens. No momento em questão, pode-se perceber também que 3 caminhões aguardam em fila para serem carregados. 


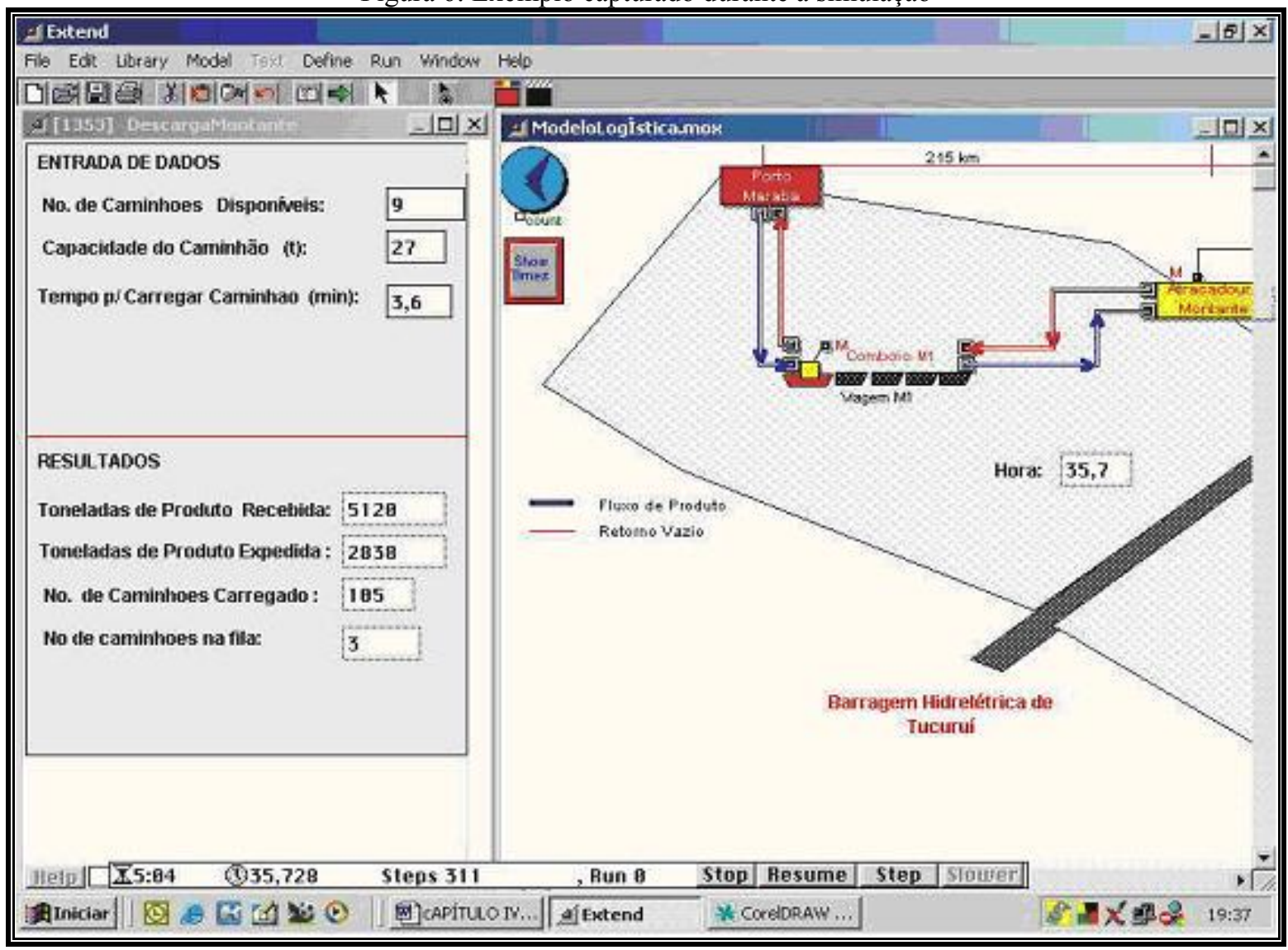

A validação do modelo foi realizada através do exame estruturado do modelo conceitual e através de consultas a especialistas. Aqui, objetivou-se garantir a veracidade e abrangência das suposições do modelo, tornando menor a probabilidade de erros.

Os especialistas consultados são profissionais dos níveis tático, estratégico e chefes operacionais de empresas de navegação e operações portuárias, logística, siderurgia e consultores de vendas de máquinas e caminhões. Estes profissionais detêm know how e vasta experiência em operações semelhantes à estudada.

As principais sugestões dos especialistas estiveram relacionadas à forma de representar o sistema de produção, como: fluxo do sistema, elos da cadeia operacional, métodos e sistemáticas logísticas.

No que se refere à validação dos dados coletados, para a construção do modelo de simulação, foi utilizado o software ARENA 10.0 para a adequação dos dados à distribuição de probabilidade correspondente. Através da ferramenta input analyser, pôde-se encontrar os parâmetros estatísticos para cada variável de entrada do sistema. Desta forma, os resultados obtidos aproximam-se significativamente da realidade, fornecendo o devido suporte ao planejamento de operações e à tomada de decisões. 


\section{Análise dos resultados}

Buscou-se utilizar o modelo implementado para o auxílio à gestão das operações na hidrovia em questão. Desta forma, o modelo foi utilizado adotando a proposição de cenários, nos quais, através de análises de sensibilidade, foi permitido obter as alternativas mais adequadas.

Neste trabalho, como todos os P-value foram superiores a 0,15 , avalia-se que todas as distribuições de aderência estão adequadas às distribuições de freqüência dos conjuntos de dados do modelo.

$\mathrm{Na}$ implementação do modelo, foi utilizada a linguagem de simulação EXTENDTM, sendo construídos sete blocos do tipo hierárquicos. Estes foram denominados: Porto de Marabá; Comboio M; Atracadouro Montante; Caminhões; Porto Jusante; Comboio J e Porto de Barcarena.

Internamente, cada um destes blocos é constituído por blocos menores, disponibilizados em bibliotecas do software EXTENDTM. Estes blocos, chamados de "blocos código" foram selecionados das bibliotecas Discrete Event, Generic e Manufacturing, com base em suas características em relação à linguagem de simulação e arranjados na tela de acordo com o layout proposto para o sistema. Em seguida, os blocos foram ligados através de conectores conforme a lógica do sistema estudado. Os dados de entrada são inseridos no modelo de acordo com as distribuições de probabilidade previamente obtidas. Segue detalhamento das funções estabelecidas para os blocos hierárquicos:

- Bloco "Porto de Marabá": Representa a operação de carregamento no terminal portuário de Marabá. Este bloco possui os seguintes objetivos: gerar o número de entidades desejadas, sendo que cada entidade representa, no modelo, uma tonelada de produto; simular e apresentar o carregamento das barcaças e a liberação do comboio a montante denominado Comboio M;

- Bloco "Comboio M1": Representa e simula o transporte hidroviário dos comboios de barcaças no trecho entre as cidades de Marabá e Tucuruí. Contabiliza o número de viagens realizadas pelos comboios no período simulado. O usuário deverá fornecer os parâmetros obtidos nas distribuições das variáveis de entrada para, durante a simulação serem reportados os valores das variáveis de saída;

- Bloco "Atracadouro a Montante": Representa a descarga dos comboios à montante da barragem da hidrelétrica de Tucuruí. Este bloco simula a capacidade dos caminhões que realizam o transbordo rodoviário, o tempo de carregamento dos caminhões, o 
número médio, máximo e mínimo de caminhões na fila a espera de carregamento;

- Bloco "Caminhões": Representa o tempo de viagem dos caminhões no modal rodoviário. Tem como função simular o tempo gasto para o caminhão levar os produtos até o pátio de estoque intermediário. Contabiliza também o número de viagens (ida e volta) dos caminhões no sistema;

- Bloco "Porto Jusante": Representa o carregamento dos comboios a jusante da barragem da hidrelétrica, a partir do pátio de estoque. Simula o nível de estoque no pátio, bem como a expedição de produtos e o tempo de carregamento das barcaças a jusante, simula também o número de partidas e chegadas de comboios, a contagem de produtos embarcados e a capacidade dos comboios;

- Bloco "Comboio J1": Representa as viagens dos comboios no trecho entre as cidades de Tucuruí e Barcarena. Tem como função simular o tempo gasto para o comboio percorrer o trecho, tanto na ida, quanto na volta. Também contabiliza o número de viagens realizadas pelos comboios;

- $\quad$ Porto de Barcarena: Representa o descarregamento das barcaças. Simula o tempo de reconstituição do comboio para a viagem de volta.

Para o entendimento do comportamento do sistema, foi realizada uma simulação, com tempo estipulado em 180 horas (um quarto de mês), a fim de se verificar o comportamento das variáveis de saída do modelo computacional implementado. De acordo com a perspectiva da gestão da operação, esse tempo corresponde aos valores encontrados na Tabela 3.

Tabela 3: Resultados gerais da simulação

\begin{tabular}{lll}
\hline Marabá & & Unidade \\
\hline $\begin{array}{l}\text { Toneladas embarcadas no trecho a montante } \\
\text { Índice de Utilização das Barcaças do trecho a } \\
\text { montante }\end{array}$ & $\begin{array}{l}22.352 \\
67,40 \%\end{array}$ & $\begin{array}{l}\text { Toneladas } \\
\text { Porcentagem }\end{array}$ \\
\hline Tucuruí Montante & Unidade \\
\hline & & \\
Quantidade de produto recebido em Tucuruí & 22.352 & Toneladas \\
Índice de utilização da frota de caminhões & $63,12 \%$ & Porcentagem \\
Tempo total de utilização dos caminhões & 113,62 & Horas \\
Máximo de caminhões em fila & 3 & Unidade \\
Mínimo de caminhões em fila & 0 & Unidade \\
\hline Tucuruí Jusante & & Unidade \\
\hline & & \\
Pátio máximo & 6.832 & Toneladas \\
Pátio mínimo & 0 & Toneladas \\
Quantidade final no pátio & 1.412 & Toneladas \\
Quantidade de Produto embarcada no trecho a jusante & 26.474 & Toneladas \\
Índice de Utilização das Barcaças do trecho a jusante & $69,73 \%$ & Porcentagem \\
\hline Barcarena & & Unidade \\
\hline
\end{tabular}




\begin{tabular}{lll}
\hline Quantidade de Produto Recebido Barcarena & 26.474 & Toneladas \\
Tempo Total da Operação & 180 & Horas \\
\hline
\end{tabular}

A partir das informações recolhidas da Tabela 3, verifica-se, inicialmente, que o sistema, simulado com base nos dados coletados, apresenta baixa utilização das barcaças de montante, o que leva a crer que há tanto uma baixa eficiência no descarregamento das barcaças, quanto capacidade produtiva ociosa. Estes pontos podem ser considerados válidos a partir de outras informações, como: a carga expedida em Marabá é a mesma recebida em Tucuruí, o que mostra que o sistema poderia possuir uma capacidade produtiva maior, uma vez que as barcaças não foram totalmente utilizadas. Outro fator considerável é o número mínimo de caminhões na fila no sistema de descarregamento dos comboios de montante, que chega a zero, deixando parado o comboio em certos períodos de tempo.

Nota-se também, em relação ao pátio de estoque situado abaixo da hidrelétrica de Tucuruí, no ponto de carregamento dos comboios de jusante, que o mesmo precisa de uma análise mais aprofundada, uma vez que seu nível de produtos chega a zero, o que gera uma ociosidade do sistema hidroviário de jusante.

Verifica-se que, até o uso de três caminhões, a frota fica completamente utilizada no sistema de descarregamento de barcaças, e que o sistema não consegue descarregar toda a carga expedida. Outro fator preponderante refere-se ao número de caminhões na fila, aguardando sua vez para carregar. É interessante que sempre haja, pelo menos, um caminhão à espera para o carregamento, uma vez que a descarga das barcaças não pode parar. Verificase que, somente a partir de cinco caminhões, é obtido este resultado. Observa-se também que, a partir de cinco caminhões no sistema, a ociosidade começa a ter considerável crescimento.

A partir de seis caminhões, o estoque, ao final da simulação, começa a decrescer. Este decréscimo se deve a uma maior eficiência no transbordo da carga. A partir de quatro caminhões, a ociosidade das barcaças de jusante aumenta, prejudicando o sistema hidroviário.

Vale salientar que, em todas as alternativas apresentadas, o estoque chega a zero em alguns momentos da simulação, o que identifica o subdimensionamento real do estoque. Além disto, nota-se o uso do material do estoque em todas as simulações, na expedição, sem uma reposição satisfatória em nenhuma situação.

Foi diagnosticada, tanto na análise geral do sistema, como na simulação da frota rodoviária, a necessidade de um estudo detalhado do estoque intermediário do sistema, uma vez que o mesmo tem de permanecer constante ou em ciclos constantes ao longo da simulação, e, primordialmente, nunca chegar ao valor de zero unidade. 
Assim como no dimensionamento da frota rodoviária de transbordo, nesta proposta de dimensionamento do estoque no pátio, consideraram-se, para toda a simulação, os resultados obtidos a partir da coleta de dados, que fornecem distribuições probabilísticas para o modelo computacional.

Observa-se, em razão das dimensões do sistema geral, que o sistema hidroviário de jusante possui capacidade superior em relação ao sistema hidroviário de montante, o que faz com que, em qualquer situação simulada com a carga expedida, baseada na coleta de dados, os comboios hidroviários de jusante absorvam parte do estoque intermediário ao final do período simulado. Este diagnóstico reforça a necessidade de um ajuste no dimensionamento da capacidade produtiva do sistema de transporte.

Verifica-se que o cenário de vinte e cinco mil toneladas encontra-se um subdimensionado para o sistema. Levando-se em consideração apenas a análise dos cenários de jusante, o valor de trinta mil toneladas expedidas estaria adequado ao modelo. Entretanto, verifica-se que, no trecho de montante, este valor não consegue chegar à cidade de Tucuruí no período estipulado. Ao longo da simulação, observa-se, porém, que o valor em torno de 28.000 toneladas expedidas satisfaz ao sistema de montante e, por estar abaixo de 30.000 toneladas, satisfaz também ao sistema de jusante.

Com esta análise, pode-se concluir que o sistema é capaz de atender, de maneira segura, uma demanda de 28.000 toneladas semanais, sem gerar espera ou super dimensionamento de carga no sistema de montante, e gerando pequena margem de ociosidade no sistema de jusante. $\mathrm{O}$ valor de 28.000 mil toneladas semanais correspondem a 1.344.000 toneladas anuais, que significam doze por cento a mais de carga que a expectativa das organizações envolvidas com o sistema, que, conforme relatado no item 5.1 deste trabalho, é de 1.000 .000 toneladas anuais.

\section{Considerações Finais}

A busca incessante por sistemas de produção cada vez mais "enxutos" e competitivos, a criação de alternativas de transporte e escoamento da produção e a reorganização da matriz de transportes brasileira são objetivos constantes no cotidiano das organizações internas. A otimização de sistemas logísticos, integrando os diversos modais de transporte, e priorizando o modal hidroviário, é uma solução necessária para o transporte de cargas pelo interior do país, sendo a solução mais competitiva para produtos de baixo valor agregado e alto volume de carga em relação aos modais predominantes no país - rodoviário e ferroviário. A 
necessidade de planejamento das hidrovias e suas operações faz-se importante, em função da potencialidade do país para este modal e da atual subutilização do transporte hidroviário como solução de escoamento de produção.

Diante da amplitude do sistema, o modelo demonstrou ser eficiente, gerando soluções coerentes, o que permitiu a representação de diferentes situações em diferentes cenários. $\mathrm{O}$ desenvolvimento sistemático dos cenários resultou em um diagnóstico capaz de auxiliar à tomada de decisão referente ao dimensionamento de subsistemas fundamentais, considerados "gargalos" para a operação modelada, que, por sua vez, estruturaram a apresentação do dimensionamento adequado da capacidade de transporte de minério de ferro por todo o sistema.

Vale ressaltar que o modelo considerado utilizou, como base para os dados de entrada, distribuições de probabilidades, o que aproximou, ainda mais, o sistema computacional à realidade, uma vez que, para cada variável, é apresentada a distribuição mais adequada àquele conjunto de dados. Esta adequação permitiu resultados mais aproximados (de acordo com a análise).

A maior limitação da aplicação do modelo está relacionada aos recursos computacionais, pois foram utilizados computadores domésticos, geralmente destinados para funções mais simples, que não exigem velocidade de processamento. A conseqüência disto foi a morosidade do sistema e a redução do período de simulação, que ficou estipulado em um quarto de mês, devido à lentidão das máquinas e à demora na geração de cada cenário estudado.

Embora a aplicação de tecnologia e a modelagem e simulação de sistemas sejam técnicas ainda pouco difundidas nas organizações da Região Amazônica, pode-se concluir que este tipo de análise assume grande importância para o planejamento de operações, servindo como instrumento sólido de apoio à gestão de operações e à tomada de decisão.

\begin{abstract}
In the state of Pará, many alternative transport have been developed. It is the multimodal transport of iron ore by the Tocantins River. The cargo, transported on a large scale by the river, suffers transshipment road only by a stretch of four kilometers in the city of Tucuruí, depending on the bus from the river. This paper proposes the application of modeling and simulation for the diagnosis and analysis of the multimodal transport system. Initially, it built a theoretical framework for the context of the transport system, the modeling and simulation. Then, the models are structured as a conceptual and computational system. The computer model that is developed in the work, are carried out sensitivity analyses by changes in the values of input variables predetermined. The evaluation of the influence of the results obtained with all stages of the system, enables one to reach a suitable operational size. Finally, suggestions and recommendations are submitted for possible deepening of this research.
\end{abstract}

Key-words: simulation; logistics; integration. 


\section{Referências}

AGÊNCIA NACIONAL DOS TRANSPORTES TERRESTRES - ANTT. Assessoria de comunicação social: números do setor. Brasília, 2004. Acesso em 13 de maio de 2008.

ANDRADE, E. L. Introdução a pesquisa operacional. $3^{\text {a }}$ Ed. Rio de Janeiro: LTC, 2004.

BANKS, J.; CARSON II, J. S.; NELSON, B. L. Discrete-event system simulation. 2. Ed. New Jersey: Prentice Hall, 1996.

BALLOU, R. H. Gerenciamento da cadeia de suprimentos: planejamento, organização e logística empresarial. Ed. Bookman, São Paulo, 2001.

BERTÁGLIA, P. R. Logística e gerenciamento da cadeia de abastecimento. São Paulo: Saraiva, 2003.

BOTTER, R. C. Introdução às técnicas de simulação e ao programa Arena. PECE. São Paulo. 2001.

CAIXETA FILHO, J. V. Transporte e logística no sistema agroindustrial. Preços agrícolas: mercados agropecuários e agribusiness. V. 10, n. 119. 1996.

CALABREZI S. R. da S. A multimodalidade para o transporte de cargas: identificação de problemas em terminais visando à integração dos modais aéreo e rodoviário. (Dissertação de Mestrado). Universidade Estadual de Campinas. Campinas, 2007.

CHRISTOPHER, M. Logística e gerenciamento da cadeia de suprimentos: criando redes que agregam valor. São Paulo: Cengage Training, 2009.

CONFEDERAÇÃO NACIONAL DOS TRANSPORTES. Pesquisa aquaviários. CNT. São Paulo, 2002. 49 p.

FARIA, A. C. ; COSTA, M. F. G. Gestão de custos logísticos. 1. ed. Sao Paulo: Atlas, 2005.

FARINA, E. M.; ZYLBERSZTAJN, D. Organização das cadeias agroindustriais de alimento. Encontro nacional de economia, 1992, Campos de Jordão. São Paulo: p. 189-207, 1992.

FLEURY, P. F. Gestão estratégica do transporte, 2002. Disponível em: $<$ http://www.cel.coppead.ufrj.br/fspublic.htm>. Acesso em: 15 mai. 2008.

FORRESTER, J. W. System dynamics and the lessons of 35 years. 1991. (Road Map n. D-4224-5). Disponível em: <http://sysdyn.mit.edu/road-maps/rm-toc.html>.

HARREL, C. R. et.al. Simulação otimizando sistemas. 2a Ed. São Paulo: IMAN, 2002.

KAPLAN, R. S.; Norton, D. P. A estratégia em ação. Rio de Janeiro: Campus, 1997.

LAW, A. M.; KELTON, W. D. Simulation modeling and analysis. 3. ed. Boston: McGraw-Hill, 2000.

LOBATO, D. C. Proposta de um ambiente de simulação e aprendizado inteligente para RAID. (Dissertação de Mestrado). USP, São Carlos, SP. Abril, 2000.

MINISTÉRIO DOS TRANSPORTES. Transportes. Disponível em: <http://www.transportes.gov.br $>$. Acesso em: 28 abr. 2008.

NOVAES, A. G. Logística e gerenciamento da cadeia de suprimentos. Rio de Janeiro: Campus, 2004.

OJIMA, A. L. R. O. Análise da movimentação logística e competitividade da soja brasileira: uma aplicação de um modelo de equilíbrio espacial de programação quadrática. 2004. (Dissertação de Mestrado). Faculdade de Engenharia Elétrica e de Computação, Universidade Estadual de Campinas, São Paulo, 2004.

OLIVA, J. A. B. O. Transporte hidroviário (Fluvial e Cabotagem) de Granéis Agrícolas. 5 Seminário Internacional em Logística Agroindustrial. ANTAQ. Piracicaba. 2008. 
PEDGEN, C. D.; SHANON, R. E.; SADOWSKI, R. P. Introduction to simulation using SIMAN. $2^{\text {a }}$ Ed. New York: McGraw-Hill, 1995.

PRADO, D. Usando o Arena em simulação. Belo Horizonte: Desenvolvimento Gerencial, 1999.

RESENDE, E. Navegação fluvial: “eclusas criarão novas vias”. Senado Federal. Brasília. 2007.

SALIBY, E.; ARAÚJO, M. M. S. Cálculo do valor em risco através da simulação de Monte Carlo: uma avaliação de uso de métodos amostrais mais eficientes em portfólios com opções. In: Simpósio Brasileiro de Pesquisa operacional, Campos do Jordão. Anais... Rio de Janeiro: Sociedade Brasileira de Pesquisa Operacional, 2001. Disponível em: <http://www.sobrapo.org.br/ simpósios/xxxiii/artigos/080-ST280.pdf.>.

SILVA, L. C. AGAIS - Armazenagem de Grãos Agro-Indústria e Simulação. Alegre, 2002. Disponível em: $<$ http://www.agais.com/simp.htm>. Acesso em: 12 mar. 2008.

SLACK, N., CHAMBERS, S.; JOHNSTON, R. Administração da produção. 2a Ed. São Paulo: Atlas, 2002.

SOARES, L. F. G. Modelagem e simulação discreta de sistemas. Rio de Janeiro: Campus, 1992. v. 1. 250 p.

YUSUF, Y. Y. et al. Agile supply chain capabilities: determinants of competitive objectives. European Journal of Operational Research, p. 379-392, 2004.

cross'ef

\section{Nome completo: Harlen dos Santos Lopes}

Filiação institucional: Universidade Federal do Ceará - UFC

Departamento: Transportes

Função ou cargo ocupado: Mestrando

Endereço completo para correspondência: Rua Coronel Linhares, 280 - apto 601 - Meireles,

Fortaleza, Ceará. CEP.: 60170-240

Telefones para contato: (85) 88910118

e-mail:harlen@det.ufc.br

Nome completo: Breno Barros Telles do Carmo

Filiação institucional: Universidade Federal Rural do semi Árido - UFERSA

Departamento: Ciências Ambientais e Tecnológicas

Função ou cargo ocupado: Professor Assistente I

Endereço completo para correspondência: Rua Coronel Linhares, 280 - apto 601 - Meireles, Fortaleza, Ceará. CEP.: 60170-240

Telefones para contato: (85) 88910118

e-mail: brenobarros@ufersa.edu.br

\section{Nome completo: Nadja Glheuca da Silva Dutra}

Filiação institucional: Universidade Federal do Ceará - UFC

Departamento: Engenharia de Transportes 
Função ou cargo ocupado: Professor Adjunto

Endereço completo para correspondência: Rua Coronel Linhares, 280 - apto 601 - Meireles, Fortaleza, Ceará. CEP.: 60170-240

Telefones para contato: (85) 88910118

e-mail:nadja@det.ufc.br

Nome completo: Heráclito Lopes Jaguaribe Pontes

Filiação institucional: Universidade Federal do Ceará - UFC

Departamento: Engenharia Mecânica e de Produção

Função ou cargo ocupado: Professor Assistente

Endereço completo para correspondência: Rua Coronel Linhares, 280 - apto 601 - Meireles, Fortaleza, Ceará. CEP.: 60170-240

Telefones para contato: (85) 88910118

e-mail:nadja@det.ufc.br

Enviado em: 20/04/2010

Aprovado em: 10/03/2011 